\title{
Acoustic Emission Feasibility Study for Carbon Epoxy Coated Aluminum Corrosion Monitoring

\author{
D. Baltzis ${ }^{1}$, O. Evaggelou ${ }^{2}$, A.G. Lekatou ${ }^{2}$ and A.S. Paipetis ${ }^{1^{*}}$
} \\ ${ }^{1}$ Composites and Smart Materials laboratory, Department of Materials Engineering, University of Ioannina, 45500, Ioannina, Greece ${ }^{2}$ Applied MetallurgyLaboratory, Department of Materials Engineering, University of Ioannina, 45500, Ioannina, Greece
}

\section{Abstract}

In the presented research effort, cyclic polarization tests were conducted coupled with acoustic emission measurements, in order to monitor the corrosion phenomena. Previous studies have shown that epoxy composite coatings offer satisfactory corrosion protection to aluminum substrates minimizing and even eliminating some degradation phenomena. In the present effort, acoustic emission was applied during potentiodynamic cyclic polarization testing on as received, anodized and carbon epoxy coated aluminum substrates in order to correlate corrosion phenomena, like oxide layer development and localized corrosion, with characteristic acoustic emission signal descriptors. The epoxy coating was used both as received and as reinforced with various carbon fillers i.e. carbon nano-tubes, amorphous graphite or a combination of them. Acoustic emission detected signals due to hydrogen bubble related processes during cathodic polarization and signals due to deposition of thick soluble films during the final stage of anodic polarization. The acoustic profile between coated and uncoated aluminum substrates, exhibited substantial changes dependent both on the surface preparation and the employed reinforcing filler. The overall outcome of the experimental results, indicate that with further research, acoustic emission can be employed as an Aluminum Corrosion Monitoring tool.

\section{Introduction}

Aluminum 2024-T3 (Al2024-T3) alloy is one of the most widely used aluminum alloys in the aerospace industry due to its relatively low weight, high strength and fatigue resistance. Typical uses of Al2024-T3 include fuselage and wing skins, cowls and internal structures. A major disadvantage of Al2024-T3 is its low corrosion resistance; hence, in aerospace applications, it is used after an anodizing treatment followed by sealing with epoxy paints/coatings $[1,2]$. Moreover, the anodization process enhances the adhesion between the aluminum substrate and the epoxy coating, however, due to electrical conductivity mismatches, in the event of a coating failure (scratches), aluminum corrosion can initiate and proceed notably fast leading to catastrophic failures [3].

In order to further enhance adhesion and alleviate the mismatches, several studies have been conducted on nano-modified epoxies employing mainly graphitic structures like carbon nano tubes (CNTs) [4-8]. Apart from the improved adhesion, CNTs can also reduce the ingress of water in the epoxy due to their hydrophobic nature and the water affected specific area resulting in more tortuous paths for the absorption and diffusion of water, thus, further enhancing the performance of the joint structure [9-11]. In addition, the CNTs can significantly enhance the electrical conductivity of the insulating epoxy, thus abating the conductivity mismatch between aluminum substrate and coating. A recent approach on epoxy resins reinforcement is via the inclusion of multiple filler types like amorphous graphite (AG) or graphene, in order to exploit synergistic effects between the fillers. When the different fillers belong to various scale sizes, it is possible to even exploit synergistic effects further enhancing performance and material properties [12-14]. In this study, AG is combined with CNTs, with the objective to explore such synergistic effects that could further improve the corrosion protection of the aluminum substrates.

In an event of corrosion initiation, an early indication could prevent catastrophic failures. Recently, many research efforts have been focused on non-destructive (NDT) on line inspection techniques that can characterize and monitor aluminum corrosion phenomena of inspection.
$[15,16]$. One of the studied techniques is that of Acoustic Emission (AE), which can monitor transient elastic propagating waves caused by a rapid release of energy within a material under stress[17,18]. AE has already been extensively employed in a wide range of engineering materials like metallic alloys [19-21], fiber reinforced polymers (FRPs) [19,22], reinforced concrete [23,24]. Recently, efforts on $\mathrm{AE}$ as a corrosion monitoring technique for steel alloys have been presented with promising results. Different corrosion phenomena, like intergranular corrosion [25], uniform [26,27], localized or pitting corrosion [21], have been successfully correlated with specific AE indices. A specific, for the aviation sector, advantage of $\mathrm{AE}$ as a corrosion monitoring technique, is that $\mathrm{AE}$ can also provide information on the structural integrity of FRPs which gradually are replacing traditional metallic alloys [28,29]. Thus, AE is emerging as a "multi-purpose"-on line monitoring tool leading to reduced costs

Based on the aforementioned considerations, in this study open circuit and cyclic polarization tests were coupled with $\mathrm{AE}$ measurements. One of the major indicators of aluminum corrosion is the formation of hydrogen as a by-product of aluminum oxide development. The coupled measurements were targeted on identifying changes in specific AE indices that could be associated with the creation of hydrogen bubbles. The employed aluminum specimens were either as-received, anodized or coated with neat and modified with carbon allotropes (i.e. carbon nano tubes (CNTS), amorphous graphite (AG) and combination (Ternary)) epoxies, so as to differentiate between

"Corresponding Author: Dr. A.S. Paipetis, Composites and Smart Materials laboratory, Department of Materials Engineering, University of Ioannina, 45500, Ioannina, Greece; Tel: +302651008001; E-mail: paipetis@cc.uoi.gr

Citation: Baltzis D, Evaggelou O, Lekatou AG, Paipetis AS (2018) Acoustic Emission Feasibility Study for Carbon Epoxy Coated Aluminum Corrosion Monitoring. Int J Metall Mater Eng 4: 143. doi: https://doi.org/10.15344/2455-2372/2018/143

Copyright: (c) 2018 Paipetis et al. This is an open-access article distributed under the terms of the Creative Commons Attribution License, which permits unrestricted use, distribution, and reproduction in any medium, provided the original author and source are credited. 
water vapor bubble phenomena and corrosion phenomena (general corrosion, pitting corrosion etc.) and correlate these phenomena with characteristic AE signal descriptors.

\section{Materials}

In this study, Al2024-T3 alloy substrates were used in the asreceived, anodized and epoxy coated states. The as-received state entails that the aluminum substrates had been sand-blasted and ultrasonically cleaned prior to electrochemical testing. However, given the fact that oxidation of the aluminum surface spontaneously occurs in the presence of the atmospheric air, it is expected that the as received substrates had a very thin (nanoscale) surface alumina-based film prior to the measurements. In the anodized state, as-received specimens were surface treated according to ASTM D 3933 without the surface sealing step, and then tested, in order to simulate a "failure type" scenario, where a protective coating is ruptured exposing the underlying anodization film. In the epoxy coated state, anodized specimens were further coated with a series of epoxy coatings. As previously stated, the epoxy coatings were as-received (neat) epoxy and reinforced with CNTs, AG and Ternary at $0.5 \%, 2.0$ and $0.5-2.0 \%$ w.w. respectively.

The epoxy resin that was used for the neat and modified coatings, was a two part low viscosity epoxy resin (Araldite 5052 resin and Aradur 5052 hardener) provided by Merkouris SA. According to the manufacturer, a typical curing cycle consisted of curing at $230 \mathrm{C}$ for 24 $\mathrm{h}$ and post curing at $1000 \mathrm{C}$ for $4 \mathrm{~h}$.

Graphistrength C100 multi walled carbon nano tubes (CNTs) MWCNTs provided by Arkema, France, and graphitie (GR) (i.e. mixture of graphite particles and chopped micron scaled carbon fibers at a $1 / 1$ ratio), provided by $R \& G$ Composites, Germany, were selected as the reinforcing phases for the modified coatings. The diameter of the CNTs ranged between 10 to $15 \mathrm{~nm}$ while the length ranged from 1 to $10 \mu \mathrm{m}$. The nanotubes were provided in the form of agglomerated bundles with an average diameter of $400 \mu \mathrm{m}$ ranging from 50 to $900 \mu \mathrm{m}$. The average size of the graphite phase laid in the range between $5 \mu \mathrm{m}$ (graphitic particles) to $50 \mu \mathrm{m}$ (chopped carbon fibers). The aforementioned carbon phases were employed individually and combined resulting to binary (CNTs-, GR-) and ternary coatings, respectively.

The dispersion method, duration and intensity was constant for all formulations, employing high speed shear mixing at 3000rpm for 3 h.The dispersion parameters were selected on the basis of the maximum fracture toughness observed for the binary CNT composites in a previous study. Further details on the dispersion procedure can be found in [9]. After the dispersion, all epoxies were mixed with the respective quantity (100/30 by weight ratio), applied with a thin brush on anodised aluminum substrates, cured at $250 \mathrm{C}$ for $24 \mathrm{~h}$ and post cured at $1000 \mathrm{C}$ for $4 \mathrm{~h}$. The thickness of all coatings was measured as $400 \pm 10 \mu \mathrm{m}$ by optical microscopy.

\section{Methods}

As received, anodised and coated substrates were then cut to rectangular specimens with dimensions of $20 \times 100 \mathrm{~mm}$ (Figure 1a). At the back side of each specimen a pico AE sensor and copper wires were attached and sealed with Teflon tape, for the electrochemical tests. The AE sensor was connected to a Mistras preamplifier, while AE Win software suite was recording the acoustic activity. The specimen was connected to an ACM Instruments Gill AC potentiostat/ galvanostat (through the copper wire) as a working electrode, with an $\mathrm{Ag} /$ $\mathrm{AgCl}\left(3.5 \mathrm{M} \mathrm{KCl}, \mathrm{E}_{\mathrm{AgCl}}=\mathrm{ESHE} 200 \mathrm{mV}\right)$ reference electrode and a platinum gauge counter electrode (Figure 2), in a typical 3-electrode electrochemical cell configuration. The front side was then covered with sealant tape leaving a surface area of approximately $1 \mathrm{~cm}^{2}$ to be exposed to aerated $3.5 \% \mathrm{NaCl}$ solution, at room temperature (RT) (Figure $1 \mathrm{~b}-\mathrm{c}$ ). a)

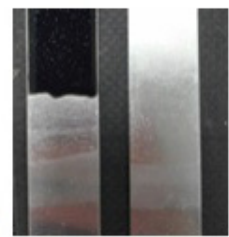

b)

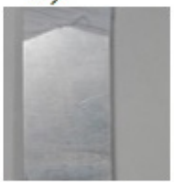

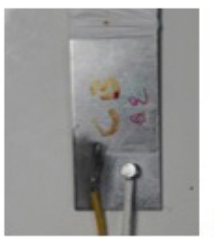

c)
Figure 1: (a) CNTS coated (left) and anodized (anodized) substrates, (b) the back side with the copper wire and AE sensor on the left and right respectively, and c) front side of the specimens.

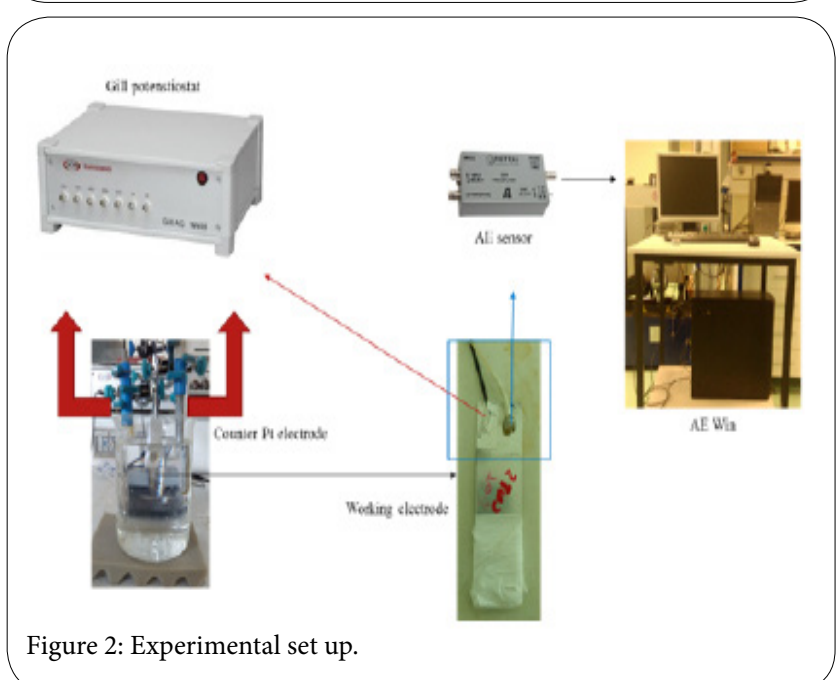

The steady state potential (Erest) was recorded during immersion in $3.5 \% \mathrm{NaCl}$ for $1 \mathrm{~h}$ (open circuit). Then, polarization started at a scan rate of $10 \mathrm{mV} / \mathrm{min}$. The susceptibility of the alloys to localized corrosion was investigated by reverse (cyclic) polarization. The main concept of this technique is that pitting would occur if the current density of the anodic portion of the return scan is higher than the current density of the forward scan for the same anodic potential [30]. This type of hysteresis is labelled as "negative hysteresis" (More details can be found in [31]).

AE was simultaneously employed in order to record all AE activity during the tests. One 'pico' type sensor connected to a Mistras Group preamplifier, was attached to the specimen using ultrasonic coupling gel. Pre-amplification and threshold values were set at $40 \mathrm{db}$ and $40 \mathrm{db}$ respectively. As-received, anodized, neat and modified epoxy coated aluminum specimens (3-5 specimens) were tested in the aforementioned order, aiming at exploring the $\mathrm{AE}$ feasibility as an aluminum corrosion monitoring tool. 


\section{Results and Discussion}

Interpretation of the anodic polarization behavior of anodized aluminum

Figure 3 presents the cyclic polarization behavior of an anodized specimen. (Here it should be noted that cathodic polarization was also carried out in order to intensify the action of localized processes by introducing cathodic reactions on the specimen). As seen from the negative hysteresis loop (i.e. reverse currents greater than forward currents for the same potential), the aluminum alloy has been subjected to localized corrosion. This can also be seen by the sharp increase in the current density (i) by almost four orders of magnitude, at potentials higher than the breakdown potential $(\mathrm{Eb})$.

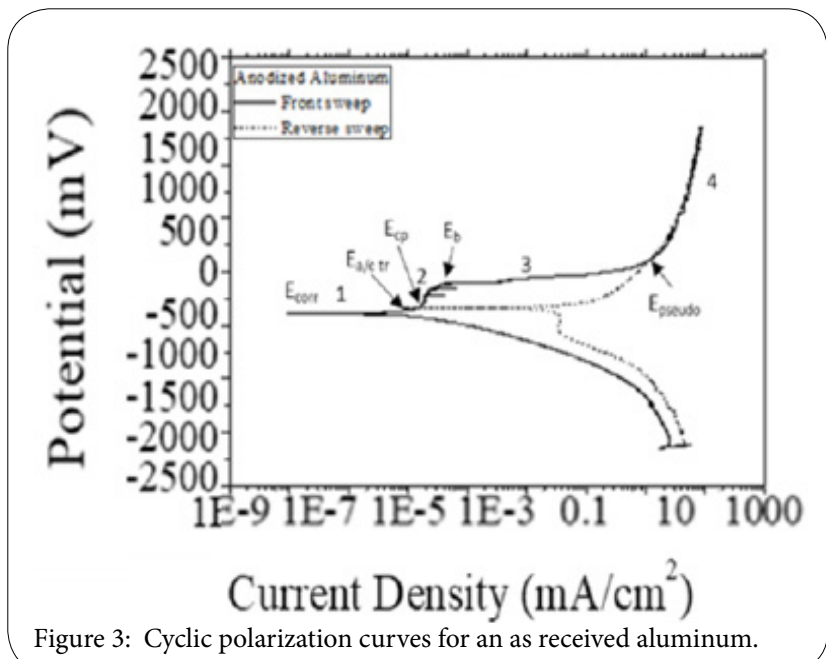

In detail, the forward anodic polarization curve of anodized Al2024 is divided in four stages:

Stage 1a: $\left(\mathrm{E}_{\mathrm{cp}}-\mathrm{E}_{\text {corr }}\right)$ : Anodic oxidation of $\mathrm{Al}$ occurs at the structural defects of the anodization film, according to the generalized reaction [32]:

$$
\mathrm{Al}+3 \mathrm{H}_{2} \mathrm{O} \rightarrow \mathrm{Al}(\mathrm{OH})_{3}+3 \mathrm{H}^{+}+3 \mathrm{e}^{-}
$$

Stage 2a: Al 2024 exhibits passivation in the potential range $E_{c p}$ (critical passivation potential) $\div$ to $\mathrm{E}_{\mathrm{b}}$ (breakdown potential) due to the phosphoric treatment. The active sites of stage 1 are covered by the long been known bi-layered structure of the passive film on aluminum: the inner layer is a compact amorphous layer whilst the outer layer is a permeable hydrated oxide layer [33].

Stage 3a $\left(E_{\text {pseud }}-E_{b}\right)$ : Passivation ends at $E_{b}$, as shown by the flat gradient sustained for almost four orders of magnitude current density increase. The breakdown of passivity may be attributed to deficient sealing of the porous upper layer of the anodic film. Full sealing by immersion in boiling water following anodization in $\mathrm{H}_{3} \mathrm{PO}_{4}$, was not applied, since it would decrease the ability of the anodic film to anchor organic coatings [34]. As the anodization film is composed of an inner denser barrier layer and an outer looser porous layer, the chloride ions can access the barrier layer through the pores. When the chloride ion concentration at the bottom of the porous layer reaches a critical level, the barrier layer begins to dissolve. Completely or partially sealing the tubular pores would reduce both the chlorine ion speed and concentration at the bottom of the porous layer. As the anodic over potential increases, the chloride concentration on the barrier layer also increases. Hence, the greater the range of passive over potentials and the lower the passive current densities, the higher the corrosion resistance of the anodization film. Nevertheless, the fact that the pitting potential is $\sim 400 \mathrm{mV}$ nobler than the corrosion potential demonstrates a moderate efficiency of the anodizing process; as for non-surface treated $\mathrm{Al} \mathrm{2024}$, the pitting potential and corrosion potential values almost coincide.

As soon as $\mathrm{Cl}^{-}$accesses the $\mathrm{Al}$ substrate having surpassed the obstructions of the anodization over layer, localized corrosion of $\mathrm{Al}$ takes place. Four steps are generally accepted to be involved in the localized corrosion of aluminum [35]:

1. The adsorption of the reactive anions on localized sites of the surface film of aluminum (i.e. sites where the film presents in homogeneities [36]).

2. The chemical reaction of the adsorbed anion with the aluminum ion in the aluminum oxide/hydroxide lattice.

3. The thinning of the oxide film by dissolution. This dissolution is a flaw assisted/ flaw centered process. (The passive film on Al-alloys exhibits semi-conductive properties owing to the non-stoichiometry of composition and local structural in homogeneities [36]).

4. The direct attack of the exposed metal by the anion possibly assisted by an anodic potential.

On the above grounds, stage 3 is interpreted as follows:

1. Once aggressive anion adsorption on the aluminum oxide surface film at the defective site occurs, an active centeris developed. In the case of Al2024, the usual film defective site is the interface between $\mathrm{Al}$ and S-phase (Al2CuMg) [37]. The latter is less noble than Al. The active center was then the site for accelerated film thinning [35].

2. Once the film is sufficiently thinned, direct attack of the exposed metallic substrate occurs. Because the film is thinned locally, the attack on the metal is also concentrated. Due to the electrochemical potential difference between $\mathrm{Al}$ and S-phase [38], localized dissolution of the anodic S-phase should occur. Nevertheless, the dissolution characteristics of the $S$ phase are complex and have been shown to incorporate a dealloying mechanism, leading to localized $\mathrm{Cu}$ enrichment. It may be assumed that the $\mathrm{S}$-phase does not dissolve as a unique entity, but may undergo a dealloying process leading to selective dissolution of the $\mathrm{Mg}$ and $\mathrm{Al}$ components of the intermetallic. The resultant $\mathrm{Cu}$ enrichment may allow for the intermetallic to behave as a local cathode after some unknown time that eventually leads to dissolution of adjacent $\mathrm{Al}$. As a consequence, small pits are formed.

3. As the pits are getting deeper, differential aeration cells are formed between the bottom of the pits and the pit walls.

Stage 4a $\left(\mathrm{E}>\mathrm{E}_{\mathrm{pseudo}}\right)$ : The hydrolysis of $\mathrm{Al}$ in microscopic and macroscopic heterogeneities according to reaction (1), results in reduction of $\mathrm{pH}$ and consequently further dissolution of Al. Diffusion of $\mathrm{Cl}^{-}$follows into the flaws to maintain electro-neutrality. The agile chlorine ions induce further hydrolysis reactions, which may lead to the formation of more $\mathrm{Al}(\mathrm{OH})_{3}[18]$ or $\mathrm{Al}(\mathrm{OH})^{2+}$ [39]. Thus, further decrease in the electrolyte $\mathrm{pH}$ in the flawed areas occurs, stimulating 
Citation: Baltzis D, Evaggelou O, Lekatou AG, Paipetis AS (2018) Acoustic Emission Feasibility Study for Carbon Epoxy Coated Aluminum Corrosion Monitoring. Int J Metall Mater Eng 4: 143. doi: https://doi.org/10.15344/2455-2372/2018/143

Page 4 of 8

further and faster aluminum dissolution. With raising potential above $\mathrm{E}_{\text {pseudo }}$, the chlorine concentration in the flawed regions increases. As a consequence, the $\mathrm{pH}$ falls to such low values, that $\mathrm{Al}$ hydroxides/ oxyhydroxides become instable [40]. At $\mathrm{E}>\mathrm{E}_{\text {pseudo }}$, the rate of formation of $\mathrm{Al}$ hydroxides/ oxyhydroxides is greater than the rate of their dissolution leading to pseudo passive stage 4 .

Although these films are heavily hydrated and soluble, as shown by the very high current densities, they seem to temporarily protect the $\mathrm{Al}$ substrate due to their thickness, as the positive hysteresis loop upon reverse polarization through stage 4 shows. As reverse scanning passes below $\mathrm{E}_{\text {pseudo }}$, the instable films dissolve and pits reopen. Thereafter, hysteresis becomes negative. The potential of anodic to cathodic transition $\left(\mathrm{E}_{\mathrm{a} / \mathrm{ctr}}\right)$ is nobler than $\mathrm{E}_{\text {corr }}$, suggesting that any current limiting process upon anodic polarization is reduced or even absent at the corrosion potential [41]. The aforementioned potential values for the as-received, anodized and coated specimens are summarized in Table 1.

\section{Polarization Behavior of Coated Aluminum Substrates}

As can be seen in Figure 4, the application of the epoxy coatings significantly enhanced corrosion protection to the aluminum substrates, in terms of shift of the polarization curves to significantly lower current densities as compared to the polarization curves of the as-received and anodized substrates (more than 2 orders of magnitude lower in the case of the hybrid coating, more than 4 orders of magnitude lower in the case of the AGR coatings and more than 1 order of magnitude lower in the case of the CNT and neat epoxy coatings. In the case of the neat epoxy and especially graphite and hybrid coatings, the polarization curves have shapes analogous to those characterizing uniform corrosion; no sharp and persistent increases in the current density (i.e. flattened curve parts) are observed whilst hysteresis loops have nil to very small surface areas. The CNT doped epoxy coating demonstrates a different polarization behavior, as will be analyzed later.
All the doped resin coatings demonstrate a conductive behavior (very low conductivity in the case of the graphite doped epoxy) attributed to the a) conductive nature of the carbon allotropic fillers and b) water uptake by the main volume of polymer and areas of deficiently cross-link density, as analytically described in previous works $[3,7,8,42,43]$. The conductive behavior of the neat epoxy coating is attributed to reason (b).

The observed differences on the curve shapes and the electrochemical values in relation to the curve of the anodized substrate in Figure 4, suggests that the electrolyte has not accessed the aluminum substrate. The modified resin coatings present nobler, as in the case of CNT coatings, or the same, as in the case of the AG coatings, anodic-tocathodic potential as compared to the corrosion potential. The current density values are significantly lower when compared to the un-coated specimens. The slightly higher current density values during the reverse polarization may be attributed to the aforementioned water uptake.

The stabilization of current at high anodic potentials may be ascribed to the saturation of the polymer with water $[3,42,43]$ and formation of unstable polymer oxidation products [44]. The absence of reinforcement/matrix interfaces in the case of neat epoxy is the reason for a more massive water uptake during reverse polarization and, consequently, notably higher reverse currents than the respective forward ones through the whore reverse scan. In the case of the filled epoxy coatings (AGR and Hybrid), the existence of many interfaces result in limitation of the "bulk" water ingress in favor of the "interfacial" water ingress. Hence, the differences between the forward current density values and the reverse current density values are much more subtle than those in the polarization curves of the neat epoxy coating. However, in the case of the CNT-modified epoxy coating, the negative hysteresis loop (of considerable area below $\mathrm{E}_{\text {pseudo }}$ ) indicates permanent effects associated with the presence of the CNTs.

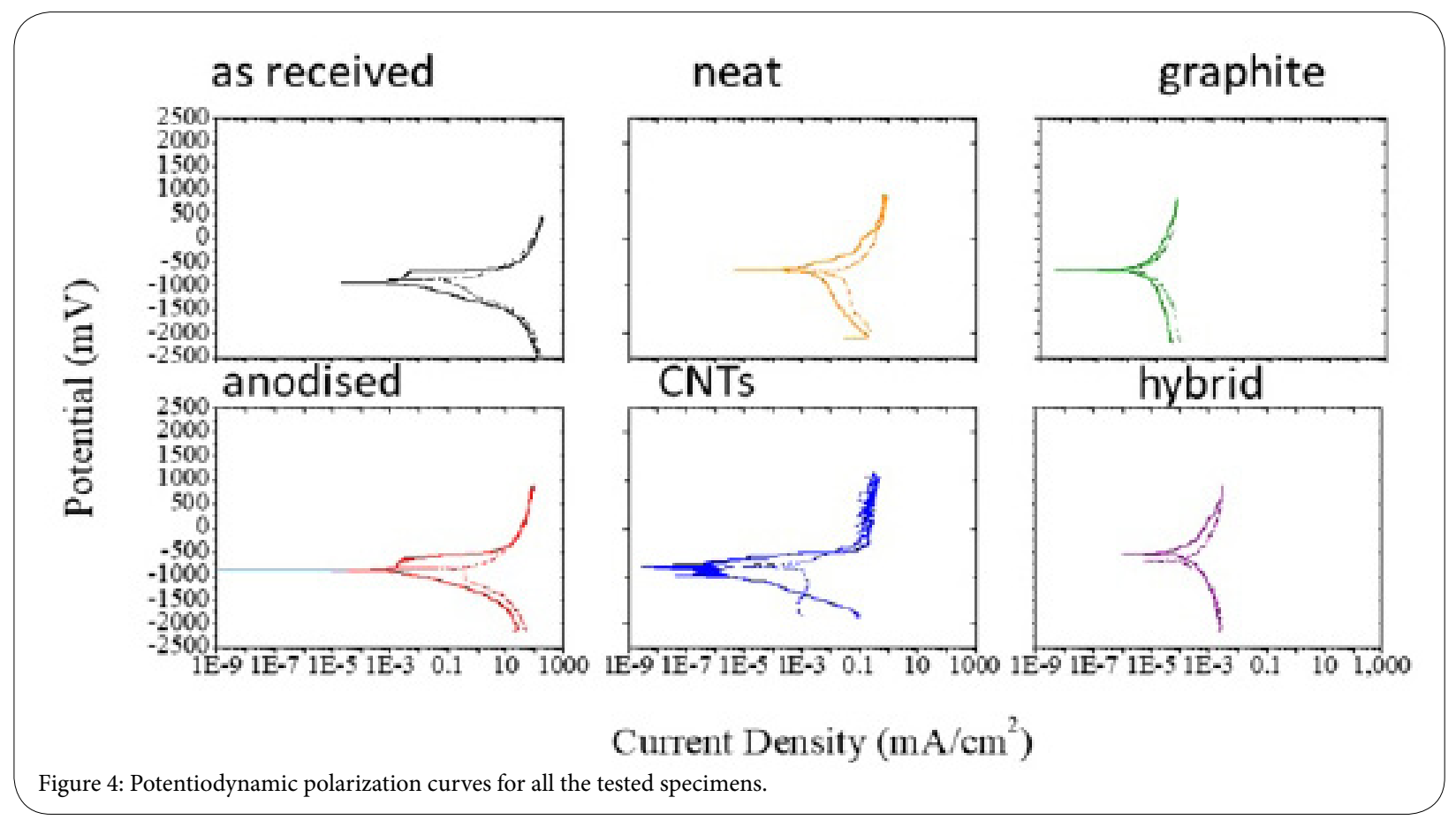


Citation: Baltzis D, Evaggelou O, Lekatou AG, Paipetis AS (2018) Acoustic Emission Feasibility Study for Carbon Epoxy Coated Aluminum Corrosion Monitoring. Int J Metall Mater Eng 4: 143. doi: https://doi.org/10.15344/2455-2372/2018/143

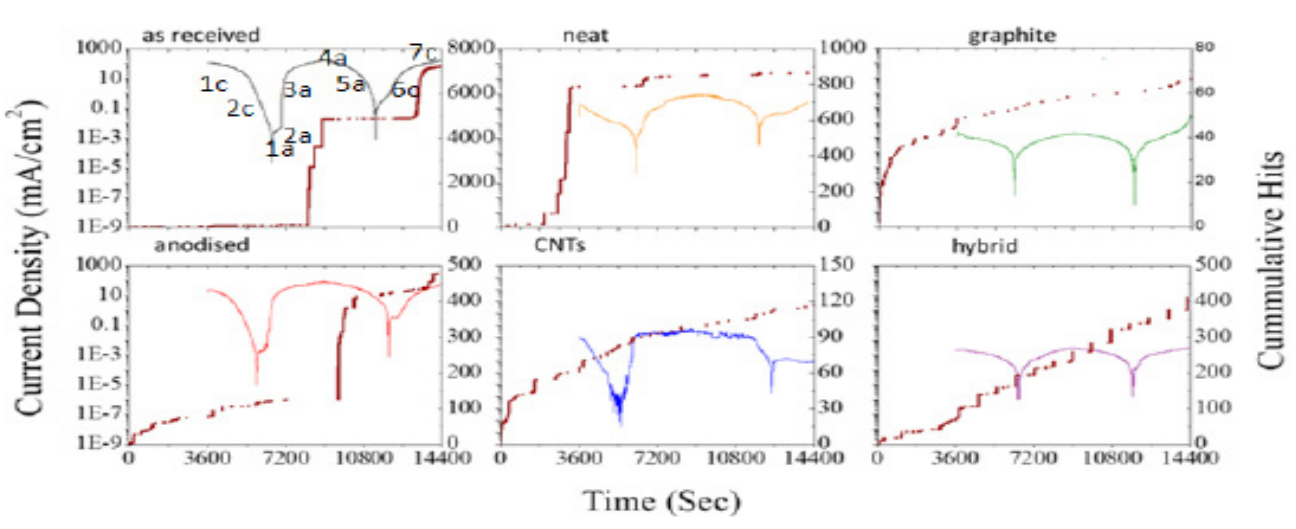

Figure 5: Current density and cumulative AE hits vs time curves for all tested specimens un-coated and coated.
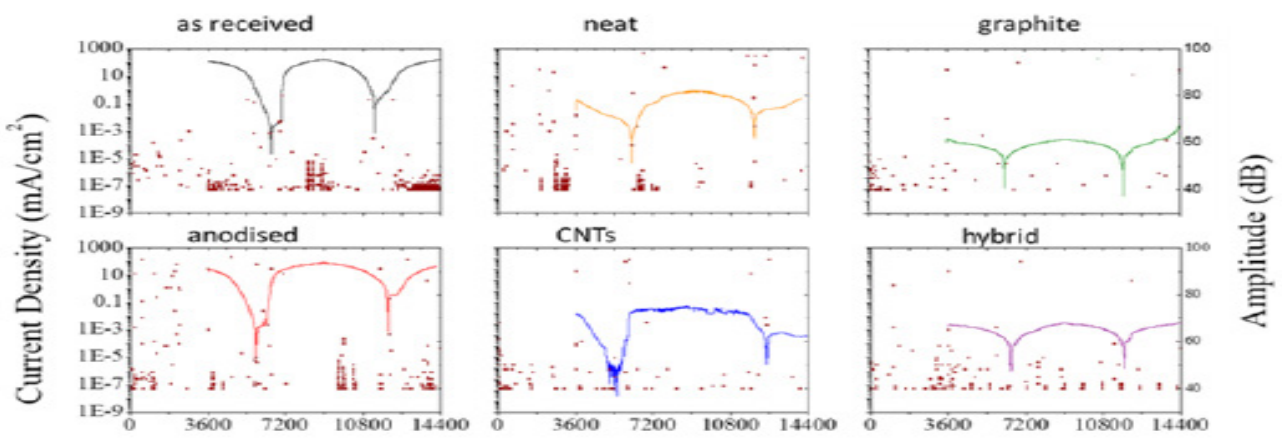

Time (Sec)

Figure 6: Current density and amplitude vs time curves for all tested specimens un-coated and coated.
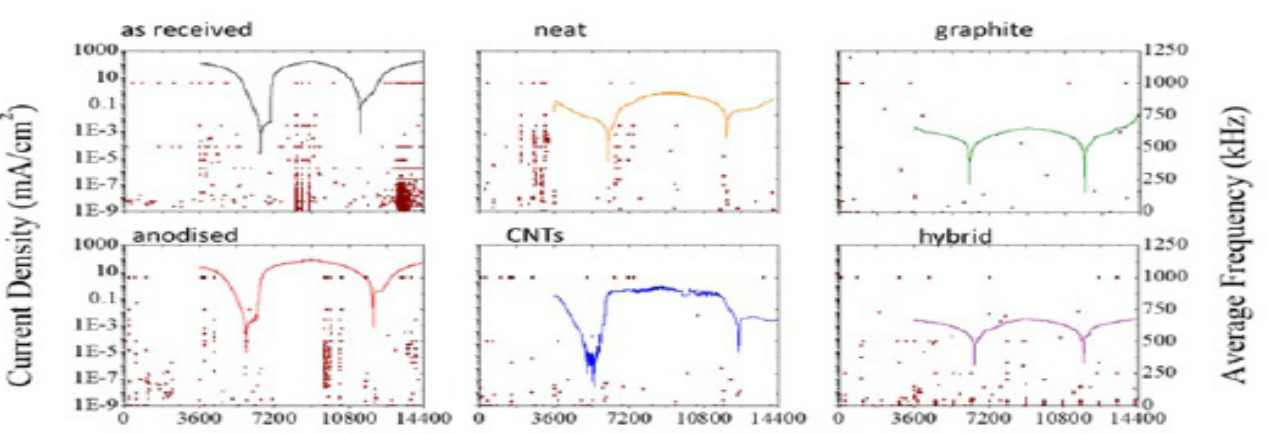

Time (Sec)

Figure 7: Current density and average frequency vs time curves for all tested specimens un-coated and coated.

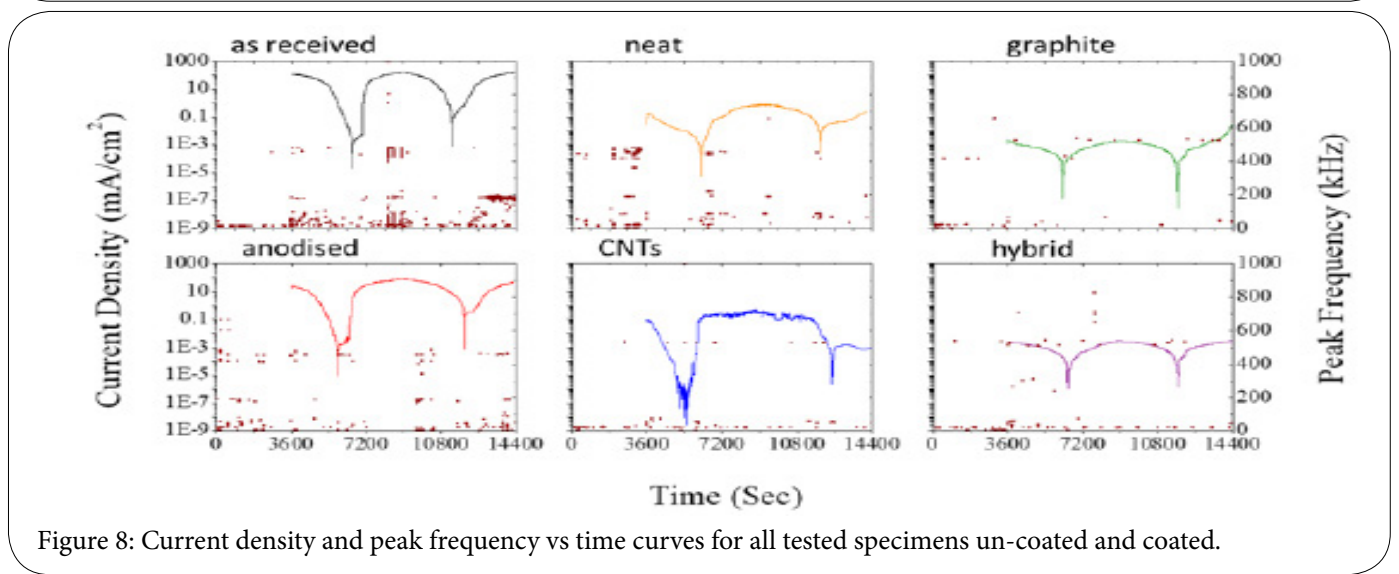


In the case of the CNTs coatings, it is seen that the polarization curve is not as smooth as in the case of the AG or ternary ones, exhibiting a spiky morphology analogous to that of metastable pitting in metals. This behavior can be attributed to the ingress of water to the vast number of interfaces between CNT particles and epoxy matrix. The water could have penetrated the interfacial areas activating the surface thus increasing current density. In analogy with the metals, the "spiky" morphology of the polarization curve at its pseudo-stabilization stage could constitute evidence of an alternating interfacial saturation (instant current decrease)/swelling (instead current increase) process, which eventually leads to a permanent swelling, as the negative hysteresis below $\mathrm{E}_{\text {pseudo }}$ suggests.

When observing the three modified coatings curves, it is evident that the hybrid coating curve presents an intermediate behavior when compared with the CNTs and AG coatings. This behavior could be an indication of synergistic effects between the fillers like the ones observed in [9]. Most important, the hybrid coating is the only one that, during the reverse cathodic polarization presents cathodic current values that are almost equal to those of the forward cathodic polarization, indicating an interactive effect of the different fillers that may eventually offset the negative effects of the water uptake.

\section{Acoustic emission and polarization curves}

Figure 5, Figure 6 and Figure 7 present cumulative AE hits, signal amplitude and average frequency respectively and current density vs time curves respectively. In figure 5 , the various corrosion stages have been marked onto the curve of the as-received Al2024 specimen for a clearer understanding.

The various corrosion stages during polarization are herein reported for a clearer correlation of the $\mathrm{AE}$ activity and corrosion process namely:

Stage 1c: cathodic forward polarization - hydrogen reduction:

$$
2 \mathrm{H}^{+}+2 \mathrm{e}^{-} \rightarrow \mathrm{H}_{2}
$$

Stage 2c: cathodic forward polarization -oxygen reduction:

$$
\mathrm{O}_{2}+2 \mathrm{H}_{2} \mathrm{O}+4 \mathrm{e}^{-} \rightarrow 4 \mathrm{OH}^{-}
$$

Stage 1a: anodic forward polarization- oxidation of $\mathrm{Al}$ according to reaction (1)

Stage 2a: anodic forward polarization-passivation at defects of anodizing film

Stage 3a: anodic forward polarization-pitting at the interface between $\mathrm{Al}$ and S-phase

Stage 4a: current stabilization by deposition of heavily hydrated alumina films on pits (pseudo passivation) during anodic forward polarization + anodic reverse polarization

Stage 5a: anodic reverse polarization-dissolution of films-pit reopening

Stage 6c: cathodic reverse polarization-oxygen reduction (reaction 3)

Stage 7c: cathodic reverse polarization-hydrogen reduction (reaction 2)
The following observations are drawn from Figures 5, 6, 7 and 8 that illustrate the AE activity versus time during cyclic polarization. First of all, it can be seen that the open circuit step of the testing resulted in insignificant AE activity.

Regarding as received Al 2024, the cumulative hit vs. time data (Figure 5) can detect activity in stage 4a (final current stabilization) and $7 \mathrm{c}\left(\mathrm{H}_{2}\right.$ reduction during reverse cathodic polarization). The amplitude vs. time data (Figure 6) can detect activity in stage 1c, primarily $\left(\mathrm{H}_{2}\right.$ reduction during forward cathodic polarization) and stage $2 c$, secondarily $\left(\mathrm{O}_{2}\right.$ reduction), stage $4 \mathrm{a}$ (forward pseudo passivation portion $)$ and stage $7 \mathrm{c}\left(\left(\mathrm{H}_{2}\right.\right.$ reduction during reverse cathodic polarization). Similarly, the average frequency vs. time data (Figure 7) can detect activity in stage 1c, primarily $\left(\mathrm{H}_{2}\right.$ reduction during forward cathodic polarization) and stage $2 \mathrm{c}$, secondarily $\left(\mathrm{O}_{2}\right.$ reduction), stage $4 \mathrm{a}$ (forward pseudo passivation portion) and stage $7 \mathrm{c}\left(\left(\mathrm{H}_{2}\right.\right.$ reduction during reverse cathodic polarization). The peak frequency vs. time data (Figure 8) can detect activity also in stages $1 c, 2 c$, stage $4 a$ (forward pseudo passivation portion) and $7 c$. To summarize, the most intensive AE activity is associated with the hydrogen reduction stages that produce hydrogen bubbling upon cathodic polarization and the final pseudo passive stage (stage 4a-forward portion). The latter follows pitting and is characterized by heavily hydrated deposits on the pits. During pitting (stage 3a), hydrogen bubbles are also generated inside the pits due to dramatic drops of $\mathrm{pH}$ realized by the depletion of $\mathrm{O}_{2}$ inside the pits, the diffusion of $\mathrm{Cl}^{-}$into the pits and hydrolysis reactions further lowering of the $\mathrm{pH}$ [46]. Therefore, it can be postulated that the recorded signals in stage $4 \mathrm{a}$ associate with hydrogen bubbling during stage $3 \mathrm{a}$, indirectly manifesting the occurrence of pitting.

Regarding the anodized Al2024, a much less AE activity, as compared to that of the as received Al2024, is observed. Cumulative $\mathrm{AE}$ hits are over than 1 order of magnitude less than the ones recorded for the as received substrate. Anodizing has limited the number of the cathodic sites (the intermetallic precipitate/ $\mathrm{Al}$ interfaces are covered by a more compact and less defective $\mathrm{Al}_{2} \mathrm{O}_{3}$ film) and the defects in the $\mathrm{Al}_{2} \mathrm{O}_{3}$ surface layer. Therefore, hydrogen bubbling due to hydrogen reduction is less. Conversely to the as-received substrate case, $\mathrm{AE}$ activity during stage $4 \mathrm{a}$ is observed only in the reverse portion of stage 4a. The reason for such behavior is not yet understood. It could be related with the following findings: a) The final current stabilization (pseudo passivation) of the anodized specimen started at $\sim 500 \mathrm{mV}$ higher than that of the as-received specimen, meaning that the $\mathrm{Cl}^{-}$ concentration at the surface of the anodized specimen is higher than that at the surface of the as-received specimen; b) Breakdown started earlier for the anodized specimen but the stabilization stage 4a lasted longer. None-the-less, the similarity in the AE signal patterns for the as-received and anodized specimens suggest similar corrosion mechanisms in compatibility with the similarity of the polarization curves.

Similar patterns were also observed in the average frequency curves for the as received and anodized aluminum. Clusters in the frequency range between $1-250 \mathrm{kHz}$ with some scattered hits at higher frequency values $(1000 \mathrm{kHz})$ are present in both aluminum types for all corrosion stages. The latter ones could be classified as environmental or electrical noise however further study should be conducted. The only differentiation that is present, can be seen during stages $6 c$ and $7 \mathrm{c}$, where in the case of the anodized specimen the recorded signals in the range from 1 to $250 \mathrm{kHz}$ are absent. 
The above-mentioned observations regarding the observed patterns in $\mathrm{AE}$ indices, give strong evidence that specific corrosion phenomena can be correlated to combinations of indices of the AE activity. The discrimination of these characteristics depend on the nature of the various corrosion related phenomena on the aluminum substrates and further studies could give a stronger indication for such a correlation.

When observing the combined potentiodynamic and AE indices curves in Figures 5 to 7 it is clear that AE activity was significantly affected by the applied epoxy coatings. All epoxy coatings exhibited significantly less AE activity when compared with the as received aluminum with the AG coating been the one with the fewest AE hits. In contrast, the hybrid coating exhibited a far greater number of $\mathrm{AE}$ hits with the CNTs being in the middle. These phenomena can be attributed to the increased number of interfaces that were present in the hybrid coating. Another interesting phenomenon is the fact that in the neat epoxy coating, almost double the AE events were recorded when compared with the anodized specimen and the hybrid coating. It is also interesting that the majority of the recorded $\mathrm{AE}$ hits, were detected during the open circuit stage, whilst during the polarization measurement notably fewer AE events occurred. These phenomena could be associated with the initial ingress of water to the bulk of the polymer that can cause swelling of the epoxy, which in turncan lead to the generation of micro cracks in the surface. Later signals in the case of the neat epoxy coating, immediately after " $\mathrm{E}_{\text {corr }}$," (Figure 6 , Figure 7, Figure 8), may be explained by water adsorption at the areas of low/defective cross-link density. These are not observed in the cases of GR, CNT and Hybrid modified epoxy coatings, suggesting that the reinforcements have filled the defective areas of the epoxy. On the other hand, the reinforced epoxy coatings present a consistently increasing trend in the cumulative AE hits vs. time curves (Figure 5), evidence of interfacial water transport.

Both CNT coating and hybrid coating exhibited a similar trend in the recorded $\mathrm{AE}$ hits with a steadily increasing rate throughout the measurements. The observed "staircase step-like" behavior could be an indication that water was being absorbed at filler/matrix interfaces activating the surface with subsequent swelling and deactivation. Given that AG coating did not exhibit such a characteristic behavior (i.e. the increasing trend was smoother and of a lower rate), this pattern can be attributed to the CNT particles.

In terms of signals amplitude (Figure 6), apart from the neat coating, all recorded $\mathrm{AE}$ events, were scattered in the range between $40 \mathrm{db}$ and $50 \mathrm{db}$ with no specific pattern emerging. This behavior further enhances the aforementioned postulation of a limited water transport through the interfaces for the modified coatings. The small cluster in the range of $40 \mathrm{db}-50 \mathrm{db}$ present in the neat coating roughly in the beginning of the anodic polarization, could be an indication of water ingress to areas of low-cross link density and subsequent formation of micro cracks in the coating surface, as aforementioned. The latter postulation could be further enhanced on closer observation of the average frequency curve of the neat coating (Figure 7). As can be seen, the cluster of signals lay in the range between $100-750 \mathrm{kHz}$, a range that in the case of the as received and anodized specimens, is present in the polarization measurement stages. This could be an indication of different phenomena between the three and an additional evidence of the AE capabilities as a corrosion monitoring tool.

More pronounced differences between the uncoated and coated specimens can be observed in Figure 8. It can be seen that the as received in the aforementioned stages exhibited signals in the frequency ranges from $1 \mathrm{kHz}$ to $150 \mathrm{kHz}, 200 \mathrm{kHz}$ and $500 \mathrm{kHz}$. As stated, these signals that were present for the anodized specimen also can be associated to the various corrosion phenomena and the by-products associated with them. In contrast, the coated specimen signals at low frequencies (up to $50 \mathrm{kHz}$ ) and high frequencies (500 $\mathrm{kHz}$ ). The medium frequencies around $200 \mathrm{kHz}$ are completely absent from the coating specimens. In combination with the aforementioned patterns of behavior for the other AE indices, it can be postulated that the observed signals can be associated with bulk water uptake and interfacial water transport and their associated degradation phenomena.

\section{Conclusions}

The following corrosion processes were identified by AE during cathodic and anodic polarization of anodized Al2024: a) hydrogen reduction during cathodic polarization, b) pseudo passivation by deposition of heavily hydrated alumina films on pits upon anodic polarization to high overpotentials. The likelihood of hydrogen evolution persistence during the final stage of current stabilization due to underlying pitting was raised. Based on the changes in the $\mathrm{AE}$ indices between the as received, anodized and coated substrates, hydrogen bubbles could be associated with low amplitude and medium peak frequency signals; pseudo passivation in terms of heavily hydrated films could be associated with low amplitude and high peak frequency signals; epoxy degradation phenomena like swelling and micro cracking could be associated with low amplitude and high peak frequency signals; reinforcement/epoxy interfacial water transport and likely degradation may be associated with a uniform and sporadic $\mathrm{AE}$ amplitude/average frequency signals. In general, the obtained experimental results, give a strong indication that $\mathrm{AE}$ can be an effective monitoring tool for aluminum corrosion studies. It has to be stated though that further investigation should be conducted so as to fully differentiate characteristic AE indices and correlate them with corrosion, epoxy and interfacial degradation phenomena.

\section{Competing Interests}

The authors have no competing interests with the work presented in this manuscript.

\section{References}

1. Fekih SM, Albedah A, Benyahia F, Belhouari M, Bouiadjra BB, et al. (2012) Optimisation of the sizes of bonded composite repair in aircraft structures. Mater Des 41: 171-176

2. Vagask A, Fechov E, Michal P, Gombar M (2016) The influence of input factors of aluminium anodizing process on resulting thickness and quality of aluminium oxide layer. Procedia Eng 149: 512-519.

3. Gkikas G, Sioulas D, Lekatou A, Barkoula NM, Paipetis AS, et al. (2012) Enhanced bonded aircraft repair using nano-modified adhesives. Mater Des 41: 394-402.

4. Fereidoon A, Kordani N, Rostamiyan Y, Ganji DD, Ahangari MG, et al. (2010) Effect of CNTs on adhesion strength of eglass/epoxy composite with alloy aluminum surface. World Appled Sci Journal 9: 204-210.

5. Khun NW, Troconis BCR, Frankel GS (2014) Effects of carbon nanotube content on adhesion strength and wear and corrosion resistance of epoxy composite coatings on AA2024-T3. Prog Org Coatings 77: 72-80.

6. Yu S, Tong MN, Critchlow G (2010) Use of carbon nanotubes reinforced epoxy as adhesives to join aluminum plates. Mater Des 31: S126-S129.

7. Baltzis D, Orfanidis S, Lekatou A, Paipetis AS (2016) Stainless Steel coupled with carbon nano-tube modified epoxy and carbon fibre composites: Electrochemical and mechanical study. Plast Rubber Compos. 
Citation: Baltzis D, Evaggelou O, Lekatou AG, Paipetis AS (2018) Acoustic Emission Feasibility Study for Carbon Epoxy Coated Aluminum Corrosion Monitoring. Int J Metall Mater Eng 4: 143. doi: https://doi.org/10.15344/2455-2372/2018/143

Page 8 of 8

8. Gkikas G, Lekatou A, Sioulas D, Paipetis AS (2014) Effect of carbon nanotube enhanced adhesives on degradation of bonded joints in corrosive environments. Plast Rubber Compos 43: 322-329.

9. Baltzis D, Bekas DG, Tzachristas G, Parlamas A, Karabela M, et al. (2017) Multi-scaled carbon reinforcements in ternary epoxy composite materials: Dispersion and electrical impedance study. Compos Sci Technol 153: 7-17.

10. Khashaba UA, Aljinaidi AA, Hamed MA (2015) Analysis of adhesively bonded CFRE composite scarf joints modified with MWCNTs. Compos Part A Appl Sci Manuf 71: 59-71.

11. Khashaba UA, Aljinaidi AA, Hamed MA (2014) Nanofillers modification of Epocast 50-A1/946 epoxy for bonded joints. Chinese J Aeronaut 27: 12881300.

12. Szeluga U, Kumanek B, Trzebicka B (2015) Synergy in hybrid polymer/ nanocarbon composites. A review. Compos. Part A Appl Sci Manuf 73: 204 231.

13. Sumfleth J, Adroher XC, Schulte K (2009) Synergistic effects in network formation and electrical properties of hybrid epoxy nanocomposites containing multi-wall carbon nanotubes and carbon black. J Mater Sci 44 3241-3247.

14. Ma PC, Liu MY, Zhang H, Wang SQ, Wang R, et al. (2009) Enhanced electrical conductivity of nanocomposites containing hybrid fillers of carbon nanotubes and carbon black. ACS Appl Mater Interfaces 1: 1090-1096.

15. Bellenger $F$, Mazille $H$, and $H$, Idrissi $H$ (2002) Use of acoustic emission technique for the early detection of aluminum alloys exfoliation corrosion. NDT E Int 35: 385-392.

16. Idrissi H, Derenne J, Mazille H. Detection of Pitting Corrosion of Aluminium Alloys By Acoustic Emission Technique.

17. Boinet M, Bernard J, Chatenet M, Dalard F, Maximovitch S, et al. (2009) Understanding aluminum behaviour in aqueous alkaline solution using coupled techniques. Part II: Acoustic emission study. Electrochim Acta 55: 3454-3463.

18. Bellenger $F$, Mazille $H$, Idrissi $H$ (2002) Use of acoustic emission technique for the early detection of aluminum alloys exfoliation corrosion. NDT E Int 35: 385-392.

19. Munoz V, Vales B, Perrin M, Pastor ML, Welemane H et al. (2016) Damage detection in CFRP by coupling acoustic emission and infrared thermography. Compos. Part B Eng 85: 68-75.

20. Strantza M, Van Hemelrijck D, Guillaume P, Aggelis DG (2017) Acoustic emission monitoring of crack propagation in additively manufactured and conventional titanium components. Mech Res Commun 84: 8-13.

21. Fregonese $M$, Idrissi $H$, Mazille $H$, Renaud L, Cetre $Y$, et al. (2001) Monitoring pitting corrosion of AISI $316 \mathrm{~L}$ austenitic stainless steel by acoustic emission technique: Choice of representative acoustic parameters. J Mater Sci 36: 557-563.

22. Masmoudi S, El Mahi A, El Guerjouma R (2014) Mechanical behaviour and health monitoring by acoustic emission of sandwich composite integrated by piezoelectric implant. Compos Part B Eng 67: 76-83.

23. Zaki A, Chai HK, Aggelis DG, Alver N (2015) Non-Destructive Evaluation for Corrosion Monitoring in Concrete: A Review and Capability of Acoustic Emission Technique. Sensors 15: 19069.

24. Farhidzadeh A, Mpalaskas AC, Matikas TE, Farhidzadeh H, Aggelis DG, et al. (2014) Fracture mode identification in cementitious materials using supervised pattern recognition of acoustic emission features. Constr Build Mater 67: 129-138

25. Xu J, Wu X, Han EH (2013) Acoustic emission response of sensitized 304 stainless steel during intergranular corrosion and stress corrosion cracking. Corros Sci 73: 262-273

26. Hwang W, Bae S, Kim J, Kang S, Kwag N, et al. (2015) Acoustic emission characteristics of stress corrosion cracks in a type 304 stainless steel tube. Nucl Eng Technol 47: 454-460.

27. Seah KHW, Chew $\mathrm{CH}$, Teoh SH (1993) The correlation of acoustic emission with rate of corrosion. 34: 1-7

28. Bak KM, Kalaichelvan K, Jothilingam A, Boopathy SR, Bak KM, et al. (2016) Acoustic emission characterization of failure modes of single-lap joints in glass/epoxy specimens. J Compos Mater 50: 3-23.

29. Bak KM, Kalaichelvan K, Arumugam V (2014) A novel approach for classification of failure modes in single lap joints using acoustic emission data. J Compos. Mater 48: 3003-3017.

30. Silverman DC (2011) Uhlig's Corrosion Handbook. 3rd ed., Wiley \& Sons, 1129-1166.

Int J Metall Mater Eng

ISSN: 2455-2372
31. Lekatou A, Sioulas D, Karatzalis AE, Grimanelis D (2015) A comparative study on the microstructure and surface property evaluation of coatings produced from nanostructured and conventional WC-Co powders HVOFsprayed on Al 7075. Surf Coatings Technol 276: 539-556.

32. Seri O (2000) Corrosion and Environmental Degradation. Wiley-VCH.

33. Hunter MS, Fowle P (1956) Naturally and thermally formed oxide films on aluminum. J Electrochem Soc 103: 482-485.

34. Altenpohl DG (1998) Aluminum: technology, applications, and environment: a profile of a modern metal. 6th edn, Washington, DC, Aluminium Association.

35. Foley RT (1986) Localized corrosion of aluminum alloys- a review. Corrosion 42: 277-288.

36. Szklarska-Smialowska Z (1999) Pitting corrosion of aluminum. Corros Sc 41: 1743-1767.

37. DeRose JA, Balkowiec A, Mchalski J, Suter T, Kurzydlowski KJ, et al. (2012) Microscopic and macroscopic characterization of an aerospace aluminum alloy (AA2024). WIT Press Southampton UK

38. Birbilis N, Buchheit RG (2005) Electrochemical characteristics of intermetallic phases in aluminum alloys: an experimental survey and discussion. J Electrochem Soc 152: 140-151.

39. Turnbull A (1983) The solution composition and electrode potential in pits, crevices and cracks. Corros Sci 23: 833-870.

40. Lekatou A, Sfikas A, Karantzalis A, Sioulas D (2012) Microstructure and corrosion performance of Al-Co alloys. Corros Sci 63: 193-209.

41. Rosen EM, Silverman DC (1992) Corrosion prediction from polarization scans using an artificial neural network integrated with an expert system. Corrosion 48: 734-745.

42. Lekatou A, Faidi SE, Ghidaoui D, Lyon SB, Newman RC, et al. (1997) Effect of water and its activity on transport properties of glass/epoxy particulate composites. Compos Part A Appl Sci Manuf 28: 223-236.

43. Lekatou A, Faidi SE, Lyon SB, Newman RC (1996) Elasticity and fracture in particulate composites with strong and degraded interface. J Mater Res 11: 1293-1304.

44. Billingham N (2008) Degradation and stabilisation of polymers.

45. McCafferty E (2005) Validation of corrosion rates measured by the Tafel extrapolation method. Corros Sci 47: 3202-3215.

46. Lekatou A, Zois D, Karantzalis AE (2010) Electrochemical behaviour of cermet coatings with a bond coat on Al7075: pseudopassivity, localized corrosion and galvanic effect considerations in a saline environment. Corrosion Science 52: 2616-2635. 